\title{
Studies on the High-Pressure Phases of Polyethylene and Poly(tetrafluoroethylene) by Raman Spectroscopy
}

\author{
Hiroshi TANAKA and Tetuo TAKEMURA \\ Faculty of Engineering, Kyushu University, \\ Hakozaki, Higashi-ku, Fukuoka 812, Japan.
}

(Received November 22, 1979)

\begin{abstract}
Raman spectroscopic investigations of the high-pressure phase in polyethylene (PE) and each phase in poly(tetrafluoroethylene) (PTFE) under high pressure were performed using a hydrostatic high-pressure optical vessel. It was found that the molecular chain in the high-pressure phase of PE contains many gauche bonds similarly to the liquid phase, and it was confirmed that this phase is like a liquid crystal, which is consistent wih the other results of X-ray, optical microscopic, and ultrasonic experiments. In the case of PTFE, the behavior of the two weak bands at 581 and $601 \mathrm{~cm}^{-1}$, whose assignment has been the subject of discussion for some time in previous literatures, was investigated in detail throughout the whole range of PTFE phase diagram. It is suggested that the bands at 581 and $601 \mathrm{~cm}^{-1}$ should be attributed to $13_{6}$ helical and transplanar conformations, respectively. Furthermore, the mechanism of untwisting in the PTFE molecular chain under high pressure is proposed.
\end{abstract}

KEY WORDS Polyethylene / Poly(tetrafluoroethylene) / High-Pressure Phase / Raman Spectroscopy / High-Pressure Optical Vessel / Liquid Crystal-Like Phase / Molecular Conformation /

The high-pressure phase of polyethylene (PE) which appears reversibly in melting and crystallization processes under high pressure above about $3000 \mathrm{~kg} \mathrm{~cm}^{-2}$ was discovered by Bassett and Turner, ${ }^{1}$ and Yasuniwa and Takemura, ${ }^{2}$ independently. The phase diagram in the melting process is shown in Figure $1 .{ }^{3}$ The structure of this phase was determined to be hexagonal (ordinary phase is orthorhombic) by Bassett and Piermarini. ${ }^{4}$ Further analyses of X-ray diffraction confirmed the existence of conformational disorder in this phase..$^{3,5}$ On the other hand, the optical microscopic observation led to the concept that this phase has a liquid crystal-like structure. ${ }^{6}$ For ascertaining of these data, a direct measurement of chain conformation in this phase by Raman spectroscopy is the best method. This direct measurement is the first objective of this paper.

The high-pressure phase of poly(tetrafluoroethylene) (PTFE) was discovered by Bridgman ${ }^{7}$ and Weir, ${ }^{8}$ independently. The complete isobaric phase diagram was obtained by Hirakawa and

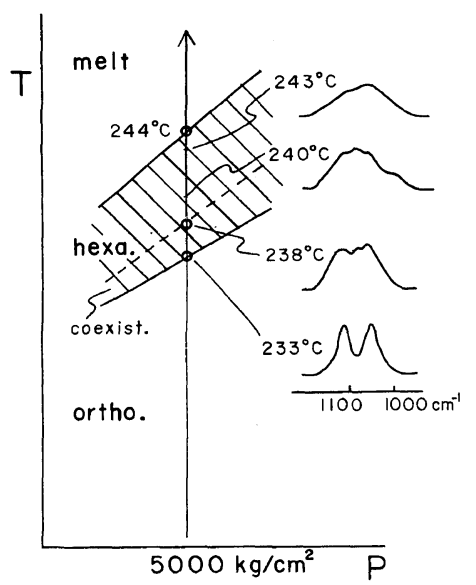

Figure 1. Schematic phase diagram of a folded-chain crystal of polyethylene. ${ }^{3}$ The region indicated by the shadow lines is the high-pressure phase (hexagonal). The region between the lower solid line and the dotted curve represents the coexistence region of the hexagonal and orthorhombic structures. The characteristics of the Raman skeletal-vibration bands are shown shcematically in this figure. 
Takemura as shown in Figure $2 .{ }^{9}$ The structure of the high-pressure phase (phase III) was proved by $\mathrm{X}$-ray fiber pattern analysis to be an orthorhombic phase with a planar zigzag conformation. ${ }^{10}$ It was

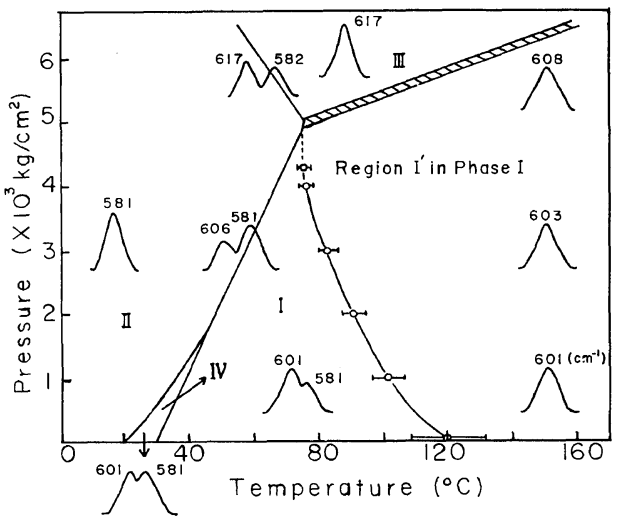

Figure 2. Phase diagram of poly(tetrafluoroethylene) ${ }^{9,13}$ Molecular packings and chain conformations of phase II, IV, I, and III are the triclinic $13_{6}$ helix, the hexagonal $15_{7}$ helix, the hexagonal disordered $15_{7}$ helix, and the orthorhombic planar zigzag, respectively. The hatched part represents the coexistence region of the orthorhombic and hexagonal crystals. The fiber pattern in the region $I^{\prime}$ in phase I shows the pattern of planar zigzag conformation. The characteristics of the Raman spectra for each phase are shown schematically in this figure.

also concluded from the physical properties in this phase that the rotational vibration of the chains in this phase is incoherent. ${ }^{11,12}$ Furthermore, the chain conformation of the region $I^{\prime}$ in phase I (hexagonal packing) was found to show a planar zigzag-like fiber pattern, ${ }^{13}$ which had been believed to be a disordered $15_{7}$ helical structure. The order of $\mathbf{I}-\mathrm{I}^{\prime}$ transition is larger than two; therefore, this nature is interpreted as coming from emphasized molecular motion about the chain axis at this boundary, according to the results of NMR experiments. ${ }^{13}$ The $\mathrm{X}$-ray diffraction pattern reflects a time-averaged molecular conformation in its long time scale, whereas the Raman spectrum reflects this in a short time scale. It is thus desirable and important to clarify the natures of phase III and the region I' in phase I by Raman spectroscopy. The clarification of these natures is the second objective of this paper.

\section{EXPERIMENTAL}

A high-pressure optical vessel with two sapphire ( $8 \mathrm{~mm}$ in diameter and $8 \mathrm{~mm}$ in length) windows, usable up to $300^{\circ} \mathrm{C}$ and $6000 \mathrm{~kg} \mathrm{~cm}^{-2}$, was constructed as shown in Figure 3. The window aperture is $4 \mathrm{~mm}$ in diameter. The high-pressure cylinder (12 $\mathrm{mm}$ in diameter) and three plugs (two window plugs and one thermocouple plug which also serves as a sample holder) were made of heat treated DBC (Yasuki Steel) and maraging steels, respectively. To prevent leakage of pressuretransmitting fluid (silicone oil, Toshiba TSF 45110 c.s.) at high temperatures, the sapphire windows were secured with an adhesive agent (Epicote 828, Mitsubishi Yuka Co.) on the optical flat surfaces of the plugs with $12^{\circ}$ tapered aperture holes. Pure hydrostatic pressure was applied to a sample by the intensifier and high-pressure pipe system. The pressure was indicated digitally with an accuracy of $\pm 10 \mathrm{~kg} \mathrm{~cm}^{-2}$ by a homemade manganine-gaugepressure meter. The focused incident beam $(4880 \AA$ or $5145 \AA$ radiation from an Ar ion laser, GLS 3200, NEC) passed through the lower window and encountered a specimen placed on the sample holder, and the $90^{\circ}$ scattered light was collected

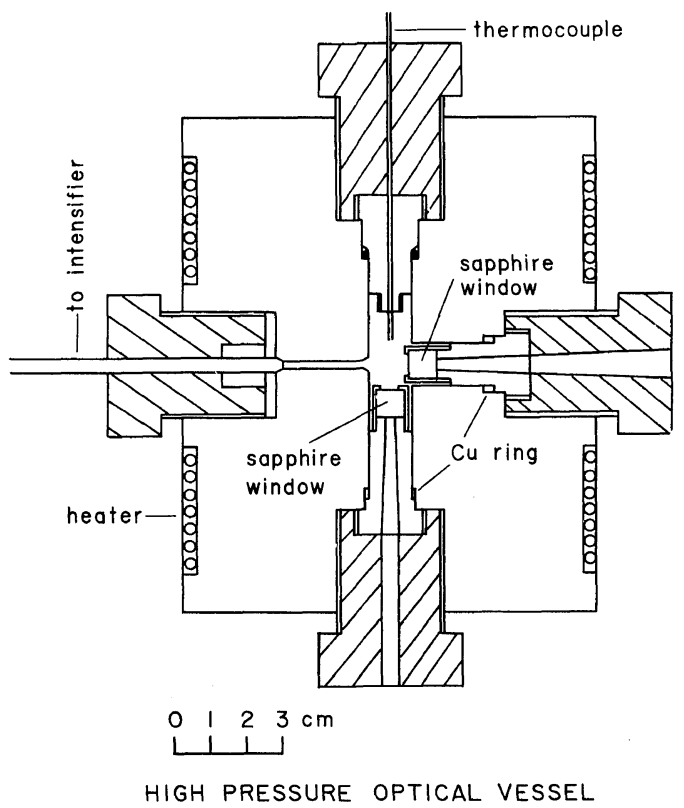

Figure 3. High-pressure optical vessel with sapphire windows. 
through the side window. The scattered light was detected by a double monochromater (CT 25 ND, Nihon Bunko Co.) and a photon counting system (PC-543A, PL-545A, NF). The wavenumber of Raman peak was determined with an accuracy of $\pm 3 \mathrm{~cm}^{-1}$.

Polyethylene samples used in this study were commercial "Hizex 2200" (Mitsui Co.) crystallized at atmospheric pressure. The sample sintered from powder "Polyflon F101" (Daikin Co.) was used as a poly(tetrafluoroethylene) sample.

\section{RESULTS AND DISCUSSION}

\section{Polyethylene (PE)}

Figure 4 shows the Raman spectra of the orthorhombic phase $\left(155^{\circ} \mathrm{C}\right)$, the lower-temperature region $\left(233^{\circ} \mathrm{C}\right)$ in the coexistence region of the orthorhombic and hexagonal structures, the upper temperature region $\left(238^{\circ} \mathrm{C}\right)$ in this region, the

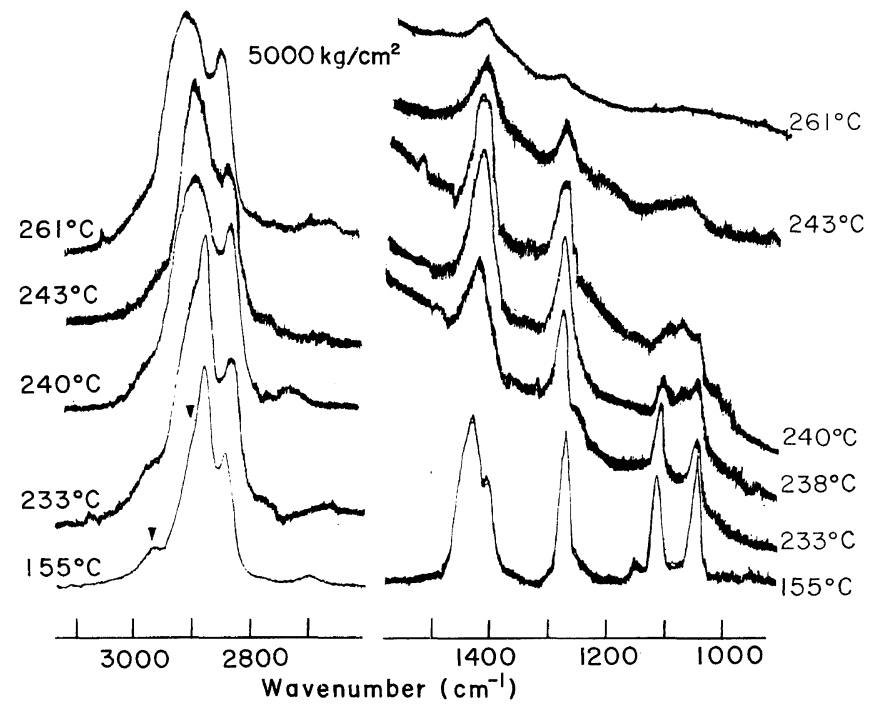

Figure 4. Raman spectra of polyethylene at $5000 \mathrm{~kg} \mathrm{~cm}^{-2}$ for the orthorhombic phase $\left(155^{\circ} \mathrm{C}\right)$, the lower-temperature region $\left(233^{\circ} \mathrm{C}\right)$ in the coexistence region, the upper region $\left(238^{\circ} \mathrm{C}\right)$ in this region, the hexagonal phase $\left(240^{\circ} \mathrm{C}\right)$, the hexagonal phase $\left(243^{\circ} \mathrm{C}\right)$ near the transition point from the hexagonal to the liquid phase, and the liquid phase $\left(261^{\circ} \mathrm{C}\right)$. The symbol $\boldsymbol{\nabla}$ denotes the Raman lines of silicone oil.

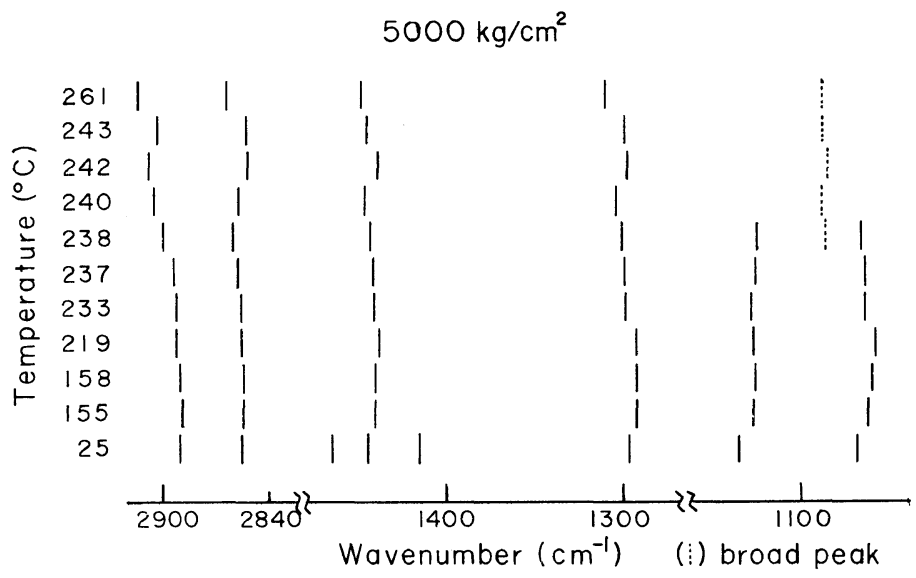

Figure 5. Temperature shifts of the main Raman bands of polyethylene at $5000 \mathrm{~kg} \mathrm{~cm}^{-2}$. 
hexagonal phase $\left(240^{\circ} \mathrm{C}\right)$, the hexagonal phase $\left(243^{\circ} \mathrm{C}\right)$ near the transition point from the hexagonal to the liquid phase, and the liquid phase $\left(261^{\circ} \mathrm{C}\right)$ at $5000 \mathrm{~kg} \mathrm{~cm}^{-2}$, respectively. Temperature shifts of the main bands are shown in Figure 5. In the orthorhombic phase, there are no temperature shifts in the $\mathrm{CH}_{2}$ stretching bands (2857 and 2889 $\mathrm{cm}^{-1}$ ), but the other bands shift slightly to lower wavenumbers. The feature of the $\mathrm{CH}_{2}$ bending bands is a well resolved triplet $(1415,1444$, and 1464 $\mathrm{cm}^{-1}$ ) at room temperature, but these lines grow into one broad peak with increasing temperature. The most important bands for understanding the chain conformational changes accompanied with the transition from the orthorhombic to the hexagonal phase are two skeletal vibration bands (1067 and $1135 \mathrm{~cm}^{-1}$ ). At the orthorhombic to hexagonal transition point $\left(233^{\circ} \mathrm{C}\right)$, obtained by the differential thermal analysis (DTA) endothermic peak (refer to Figure 1), these two bands begin to lose their intensities and take on a broad base curve. At the upper point $\left(238^{\circ} \mathrm{C}\right)$ of the coexistence region, a new broad band appears at about 1085 $\mathrm{cm}^{-1}$ at the center of the two weakened skeletal vibration bands. At the pure hexagonal phase $\left(240^{\circ} \mathrm{C}\right)$, the $1135 \mathrm{~cm}^{-1}$ band moves to a broad band located at $1000 \mathrm{~cm}^{-1}$, and the $1067 \mathrm{~cm}^{-1}$ band forms a large broad band located at $1085 \mathrm{~cm}^{-1}$. The broadening of these bands is accelerated at temperatures above the melting point of the hexagonal phase $\left(244^{\circ} \mathrm{C}\right)$ which is observed as DTA endothermic peak.

These facts can be explained by the use of a frequency dispersion map for a polyethylene chain. According to the theoretical calculation of these skeletal vibration modes ( $v_{4}$ branch) by Tasumi et al. ${ }^{14}$ the wavenumber of this branch has a value of $1135 \mathrm{~cm}^{-1}$ at $\delta=0$, decreases gradually with increasing $\delta$ to the minimum value of about 1000 $\mathrm{cm}^{-1}$ at $\delta=4 \pi / 9$, increases gradually to the maximum value of about $1085 \mathrm{~cm}^{-1}$ at $\delta=7 \pi / 9$, and tends to $1067 \mathrm{~cm}^{-1}$ at $\delta=\pi$. For the planar zigzagchain conformation, the Raman active frequencies in this branch are restricted to 1135 and $1067 \mathrm{~cm}^{-1}$ which correspond to the values at $\delta=0$ and $\pi$, respectively. When the number of gauche bonds in the chain increases, the selection rule will be destroyed, and accoding to the zeroth approximation, the 1135 and $1067 \mathrm{~cm}^{-1}$ bands will spread to the minimum $\left(1000 \mathrm{~cm}^{-1}\right.$ at $\left.\delta=4 \pi / 9\right)$ and the maximum $\left(1085 \mathrm{~cm}^{-1}\right.$ at $\left.\delta=7 \pi / 9\right)$ frequencies of this branch, respectively. ${ }^{26}$ These facts can be seen in Figure 4 as well as Figure 1 in which temperature dependence of these skeletal bands is schematically summarized in relation to the phase diagram. Thus, the molecular chain in the high-pressure phase must contain many gauche bonds similarly to the liquid phase. But, this phase has a hexagonal structure. This phase can thus be considered to be like a liquid crystal. This conclusion supports the results of Xray measurements ${ }^{3}$ and the optical microscopic observation ${ }^{6}$ mentioned in the introduction of this paper. Further support for the liquid crystal-like nature of the hexagonal phase is given by the results of ultrasonic measurements ${ }^{15}$ that the shear modulus of high-pressure phase is the same as that of the liquid phase.

Why does a liquid crystal-like high-pressure phase exist above about $3000 \mathrm{~kg} \mathrm{~cm}^{-2}$ ? The answer to this question is very interesting, but also very difficult. However, a certain amount of pressureinduced cross-linking will play a role in determining the appearance of the hexagonal phase prior to melting under high pressure. Thiat is, certain defects due to crossing of the molecular chains in the crystal will act as pressure induced cross-linking and prevent the melting of the orthorhombic phase. ${ }^{27}$

\section{Poly(tetrafluoroethylene) (PTFE)}

The Raman spectra of phase II, III (high-pressure phase), and the region $I^{\prime}$ in phase $I$ at $5500 \mathrm{~kg} \mathrm{~cm}^{-2}$ are shown in Figure 6. There are no remarkable changes between these spectra, except the slight temperature shifts of each peak. Similar results were obtained at 4000,3000 , and $2000 \mathrm{~kg} \mathrm{~cm}^{-2}$, and at atmospheric pressure. However, some characteristic changes can be observed for two weak peaks at 617 and $582 \mathrm{~cm}^{-1}$. The details of the behaviour of these bands under 5500 and $3000 \mathrm{~kg} \mathrm{~cm}^{-2}$, and under atmospheric pressure are shown in Figure 7. At $5500 \mathrm{~kg} \mathrm{~cm}^{-2}$, the peak height of the $582 \mathrm{~cm}^{-1}$ band $\left(35^{\circ} \mathrm{C}\right)$, which seems to characterize the $13_{6}$ helical conformation of phase II, decreases rapidly and disappears at the II-III transition temperature $\left(71^{\circ} \mathrm{C}\right)$, while the $617 \mathrm{~cm}^{-1}$ band $\left(79^{\circ} \mathrm{C}\right)$, which seems to characterize the planar zigzag conformation of phase III, appears at this temperature and its intensity increases rapidly with increasing temperature. This peak maintains a constant intensity up to the region $\mathrm{I}^{\prime}$ with a gradual wavenumber shift 


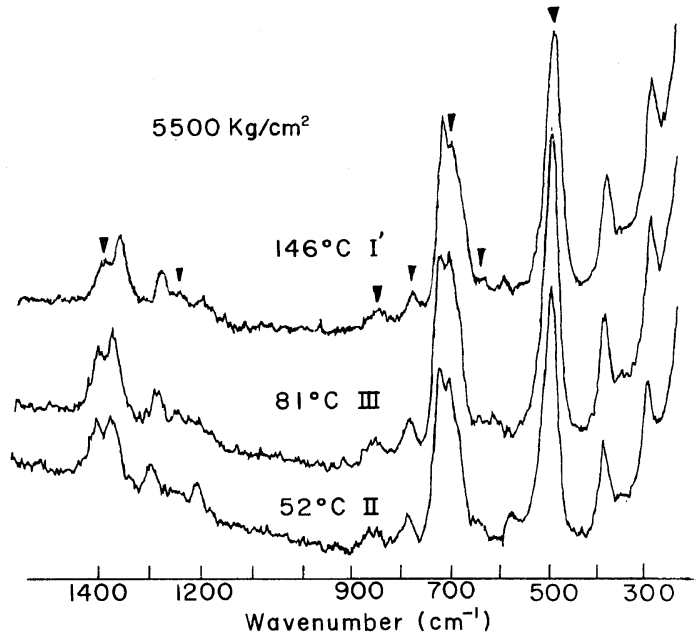

Figure 6. Raman spectra of poly(tetrafluoroethylene) at $5500 \mathrm{~kg} \mathrm{~cm}^{-2}$ for phase II, III, and the region $\mathrm{I}^{\prime}$ in phase I. The symbol $\boldsymbol{\nabla}$ denotes the Raman lines of silicone oil.

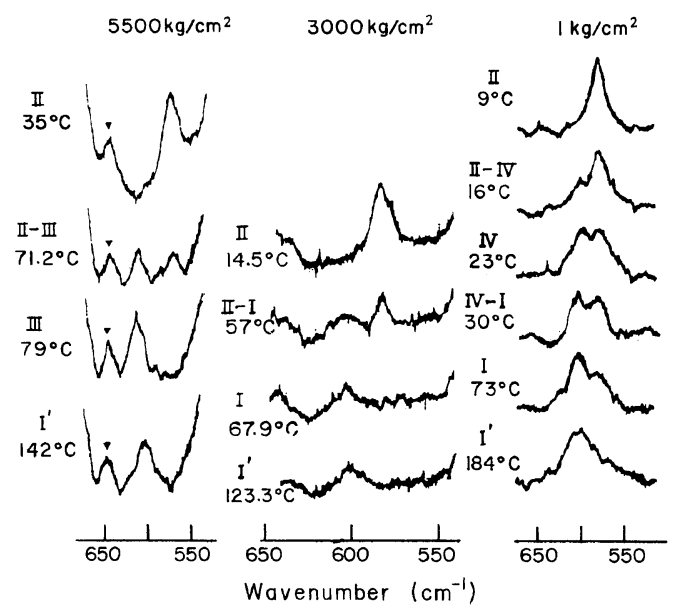

Figure 7. Raman spectra of poly(tetrafluoroethylene) at 5500 and $3000 \mathrm{~kg} \mathrm{~cm}^{-2}$, and at atmospheric pressure in the $550-650 \mathrm{~cm}^{-1}$ range.

to $608 \mathrm{~cm}^{-1}\left(142^{\circ} \mathrm{C}\right)$ at the III-I' transition region. At $3000 \mathrm{~kg} \mathrm{~cm}^{-2}$, the peak height of the $581 \mathrm{~cm}^{-1}$ band $\left(14.5^{\circ} \mathrm{C}\right)$, which seems to characterize pahse II, decreases gradually from the II-I transition range $\left(57^{\circ} \mathrm{C}\right)$ to the $\mathrm{I}-\mathrm{I}^{\prime}$ transition range $\left(85^{\circ} \mathrm{C}\right)$, while the $606 \mathrm{~cm}^{-1}$ band $\left(67.9^{\circ} \mathrm{C}\right)$, which seems to characterize the disordered $15_{7}$ helical structure, appears at the II-I transition range and maintains a constant intensity up to the region $\mathrm{I}^{\prime}$ with a slight wavenumber shift to $603 \mathrm{~cm}^{-1}\left(123.3^{\circ} \mathrm{C}\right)$ at the I-I' transition range. At atmospheric pressure, the peak height of the $581 \mathrm{~cm}^{-1}$ band decreases very gradually over from the II-IV transition range to the I-I' transition range $\left(120^{\circ} \mathrm{C}\right)$, while the $601 \mathrm{~cm}^{-1}$ band appears rapidly at the II-IV transition range and maintains a constant intensity up to the region $I^{\prime}$. These characteristics are summarized schematically in Figure 2 with relation to the phase diagram.

The appearance of the $617 \mathrm{~cm}^{-1}$ band at the IIIII transition point was reported as a characteristic of the planar zigzag phase by Wu et al ${ }^{16}$ and Rabolt et al. ${ }^{17}$, based on their isothermal measurements at room temperature. Wu et al. interpreted this appearance as the wavenumber shift of the 582 $\mathrm{cm}^{-1}$ band due to the change in atomic contact induced by this first-order transition.

On the other hand, the appearance of the 601 $\mathrm{cm}^{-1}$ band at $20^{\circ} \mathrm{C}$ under atmospheric pressure is suggested as aristing from a thermal defect, which is the reversal of the pitch of the helix, i.e., the change from a left-handed to a right-handed helix, by DeSantis et al. ${ }^{18}$ Brown, ${ }^{19}$ Koenig et al.,${ }^{20}$ Hannon et al., ${ }^{21}$ and Zerbi et al. ${ }^{22}$

Regarding the results concerning low-molecular fluorocabons, Koenig and Boerio ${ }^{23}$ reported that the 581 and $601 \mathrm{~cm}^{-1}$ bands should be attributed to the deformation of $\mathrm{CH}_{2}$ groups adjoining transplanar and gauche backbone linkages, respectively. However, they finally reported that the 581 $\mathrm{cm}^{-1}$ band has to be assigned to a fundamental vibration of $13_{6}$ helix, based on the fact that it splits at low temperatures. ${ }^{24}$

Clark $^{25}$ reported a model based on this helix reversal point and interpreted the results of X-ray and NMR measurements. According to his model, these helix reversal points with transplanar conformation segregate into planes perpendicular to the chain axis forming the boundaries between the leftand right-handed crystal domains below the $20^{\circ} \mathrm{C}$ transition temperature, but above this temperature, such dislocation planes in the crystal gradually become more disordered as a result of the diffusion of the helix reversal points.

It is very disappointing that the vibrational assignment for PTFE chain is not complete. Particularly, the assignment of these two weak bands has been the subject of speculation and discussion for some time. In this paper, however, the 
systematic investigation of the characteristic behaviour of these two bands over the whole range of the phase diagram is performed for the first time. As the character of these bands are shown schematically in Figure 2, our results must assign the 581 $\mathrm{cm}^{-1}$ band to a fundamental vibration $\mathrm{f} 13_{6}$ helix as Koenig's final report must also do and the $617 \mathrm{~cm}^{-1}$ band to a fundamental vibration or overtone of transplanar chain since it appears at the planar zigzag orthorhombic phase (phase III). Furthermore, the $601-608 \mathrm{~cm}^{-1}$ bands in phase IV, I, and the region $\mathrm{I}^{\prime}$ must be attributed to the thermal defect with transplanar conformation, since, at the II-IV and II-I transition temperatures, the abrupt growth of these bands is accompanied with an increase in rotational vibration along the chain axis, in phase $I$, the gradual decrease in the $581 \mathrm{~cm}^{-1}$ band intensity progresses with increasing temperature, and at the boundary of region $\mathrm{I}^{\prime}$, the disappearance of this band can be observed along with a slight additional increase in rotational vibration along the chain axis. ${ }^{13}$

In view of our conclusions, Clark's model should be rewritten as follows: the helix reversal dislocation plane composed of $\mathrm{C}-\mathrm{C}-\mathrm{C}$ in the trans position below the $20^{\circ} \mathrm{C}$ transition grows and then unravels the chain from a $13_{6}$ to a $15_{7}$ helical symmetry at the $20^{\circ} \mathrm{C}$ transition. The helix reversal region (transplanar region) then grows and migrates along the chain axis at the $30^{\circ} \mathrm{C}$ transition, and spreads out over the chain at the boundary of the region $\mathrm{I}^{\prime}$ in phase I. This feature can be understood by the following ordinary example. A vertically loosely stretched wet towel which is twisted into a righthanded helix in its upper part and into a left-handed helix in its lower part, is plane at the center, (this corresponds to the feature below the $20^{\circ} \mathrm{C}$ transition). When stretched (corresponding to an increase in the internal pressure due to emphasized thermal vibrational energy of the helical chain), the towel untwists and the plane portion spreads out over the towel (corresponding to the feature above the $20^{\circ} \mathrm{C}$ transition). Furthermore, the planar zigzag-like conformation obtained by $\mathrm{X}$-ray measurements may be caused by a further untwisting of the helix in the region $\mathrm{I}^{\prime}$.

\section{CONCLUSION}

The molecular conformational changes of PE and
PTFE under high pressure and temperature are shown in this study, and the major conclusions may be summarized as follows.

\section{$P E$}

The molecular chain in the high-pressure phase (hexagonal phase) of PE contains many gauche bonds as is the case in the liquid phase. This phase can therefore be considered as being like a liquid crystal, and this is consistent with the other results of X-ray, ${ }^{3}$ optical microscopic, ${ }^{6}$ and ultrasonic ${ }^{15}$ experiments. A certain amount of pressure-induced cross-linking will play a roll in determining the appearance of this liquid crystal-like phase prior to melting under high pressure.

\section{PTFE}

The $581 \mathrm{~cm}^{-1}$ band in phase II and the $617 \mathrm{~cm}^{-1}$ band in phase III must be assigned to a fundamental vibration of $13_{6}$ helix and to a fundamental vibration or overtone of the transplanar conformation, respectively. Furthermore, the $601-608$ $\mathrm{cm}^{-1}$ bands in phase IV, I, and the region $\mathrm{I}^{\prime}$ can be considered as arising from thermal defects of the helix reversal points with transplanar conformation. The helical chains in phase IV and I unravel gradually with increasing temperature because of the increased internal pressure due to the emphasized thermal vibrational energy of the chains, and at the same time, the helix reversal region (transplanar region) grows and spreads out over the chains.

Acknowledgements. This work was supported by a Grant-in-Aid for Scientific Research from the Ministry of Education, Science and Culture.

\section{REFERENCES}

1. D. C. Bassett and B. Turner, Nature Phys. Sci., 246, 146 (1972); Phil. Mag., 29, 925 (1974).

2. M. Yasuniwa and T. Takemura, Polym. J., 4, 526 (1973).

3. M. Yasuniwa, R. Enoshita, and T. Takemura, Jpn. J. Appl. Phys., 15, 1421 (1976).

4. D. C. Bassett, S. Block, and G. J. Piermarini, J. Appl. Phys., 45, 4146 (1974).

5. T. Yamamoto, H. Miyaji, and K. Asai, Jpn. J. Appl. Phys., 16, 1891 (1977).

6. M. Yasuniwa and T. Takemura, Polymer, 15, 661 (1974). 
7. P. W. Bridgman, Proc. Am. Acad. Arts Sci., 76, 71 (1948).

8. C. E. Weir, J. Res. Natl. Bur. Stand., 46, 207 (1951).

9. S. Hirakawa and T. Takemura, Jpn. J. Appl. Phys., 8, 635 (1969).

10. C. Nakafuku and T. Takemura, Jpn. J. Appl. Phys., 14, 599 (1975).

11. K. Matsushige, S. Hirakawa, and T. Takemura, Mem. Eng. Kyushu Univ., 32, 153 (1972).

12. C. Nakafuku, S. Taki, and T. Takemura, Polymer, 14, 558 (1973).

13. K. Matsushige, R. Enoshita, T. Ide, N. Yamauchi, S. Taki, and T. Takemura, Jpn. J. Appl. Phys., 16, 681 (1977).

14. M. Tasumi, T. Shimanouchi, and T. Miyazawa, $J$. Mol. Spectrosc., 9, 261 (1962).

15. K. Nagata, K. Tagashira, S. Taki, and T. Takemura, Jpn. J. Appl. Phys., 19, 985 (1980).

16. C. K. Wu and M. Nicol, Chem. Phys. Lett., 21, 153 (1973).
17. J. F. Rabolt, G. Piermarini, and S. Block, J. Chem Phys., 69, 2827 (1978)

18. P. DeSantis, E. Giglio, A. M. Liquori, and A. Ripamonti, J. Polym. Sci., A, 1, 1383 (1963).

19. R. G. Brown, J. Chem. Phys., 40, 2900 (1964).

20. J. L. Koenig and F. J. Boerio, J. Chem. Phys., 50, 2823 (1969).

21. M. J. Hannon, F. J. Boerio, and J. L. Koenig, J. Chem. Phys., 50, 2829 (1969).

22. G. Zerbi and M. Sacchi, Macromolecules, 6, 692 (1973).

23. J. L. Koenig and F. J. Boerio, J. Chem. Phys., 52, 4170 (1970).

24. F. J. Boerio and J. L. Koenig, J. Chem. Phys., 54, 3667 (1971).

25. E. S. Clark, J. Macromol. Sci., Phys., B1, 795 (1967).

26. K. Shiokawa and T. Oyama, Rep. Prog. Polym. Phys. Jpn., 14, 163 (1971).

27. K. Matsushige and T. Takemura, J. Cryst. Growth, 48, 343 (1980). 